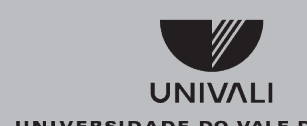

UNIVERSIDADE DO VALE DO ITAJAÍ

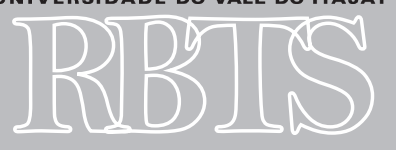

Revista Brasileira de Tecnologias Sociais
* Possui graduação em Direito pela Universidade Estadual Vale do Acaraú (2009). Especialização em Processo Civil pela Universidade Estadual Vale do Acaraú (2013) e Mestre em Direito pela Universidade Federal de Santa Catarina (2017).

** Possui graduação em Direito pela Pontifícia Universidade Católica do Rio Grande do Sul (1983), especialização em Sociologia Política pela Universidade Federal de Santa Catarina (1987), mestrado em Direito pela Universidade Federal de Santa Catarina (1988), doutorado em Sociologie Et Anthropologie Du Politique pela Université Paris 8 - Vincennes-Saint-Denis (1994) e pós-doutorado pela Universidade Lusíada de Lisboa (2012).

\section{O DIREITO COMO LIMITADOR DO PODER DO ESTADO}

\section{LAW AS A FACTOR THAT LIMITS THE POWER OF THE STATE}

\author{
José Wellington Parente Silva* \\ Rogério Portanova**
}

RESUMO: A presente pesquisa teve como objeto o estudo do Direito como um dos principais fatores limitadores do poder do Estado, uma vez que os seres humanos precisavam de normas que disciplinassem suas condutas. Assim, sentiu-se a necessidade de analisar como a civilização antiga se organizou para o surgimento do Estado. Dessa maneira, vários autores buscaram criar teorias para explicar quando e como os homens criaram a figura estatal. Desde uma concepção de contrato social até uma teoria mais moderna de sua gênese. Da mesma maneira, procurou-se entender os direitos que o Estado tutela diante das ações individuais, uma vez que ele busca disciplinar as ações humanas e essas ações são reflexos dos poderes que o possui, por não se possuir um poder absoluto, uma vez que os entes, quando possuem vários poderes, tendem a abusar desses poderes. Por esse motivo, o direito entra em cena para tentar limitar o poder absoluto do ente estatal, pois como se sabe, esse poder é representado por pessoas e possuem uma carga enorme de opiniões e subjetivismo. Assim, é por meio do Direito que se restringe o direito do estado diante da coletividade. Dessa maneira, para que se conseguisse uma reafirmação da ideia ora lançada, houve consulta a Kelsen (1999), a Reale (2001), a Dallari (2012), a Mendes (2009), entre outros, para que, a partir dos pensamentos desses autores renomados no assunto, se pudesse entender a melhor aplicabilidade das normas jurídicas na sociedade, assim como se buscar o respeito social por meio do poder do Estado, que disciplina os seres humanos e respeita os direitos individuais, coletivos e sociais.

Palavras-Chave: Estado; Poder; Direito e Limitação.

ABSTRACT: The object of study of this research is the Law as one of the main limiting factors of state power, as human beings need rules to discipline their conduct. Thus, it was felt that there was a need to analyze how ancient civilization was organized for the emergence of the State. Various authors have attempted to create theories to explain when and how men created the concept of State, from a concept of social contract through to a more modern theory of its origins. Similarly, we sought to understand the rights that the state protects in the face of individual actions, as it seeks to discipline human actions. These actions are a reflection of the powers that it has, as it does not have absolute power, given that entities, when they have various powers, tend to abuse 
these powers. For this reason, the law steps in to try to limit the absolute power of the state entity, because as we know, this power is represented by people, with their vast array of opinions and subjectivism. Thus, it is through the Law that the law of state is restricted in the community. To reaffirm the idea proposed here, we consulted Kelsen (1999), Reale (2001), Dallari (2012), and Mendes (2009), among others, so that based on the thoughts of these renowned authors on the subject, it might be possible to understand the best applicability of legal rules in society, and to seek social respect through state power, which governs human beings and respects individual, collective and social rights.

Keywords: State; Power; Law and Limitation. 


\section{INTRODUÇÃO}

Muitas observações avaliadas por teóricos mostram a necessidade de uma pesquisa que esclareça melhor como o Direito é utilizado como limitador do Poder do Estado. Já que existem muitas concepções de criação do Estado, é preciso que, além de se possuir a figura estatal, é importante que este estado esteja disciplinado para que tenha a finalidade de aplicar as normas levando em consideração o bem comum.

Este estudo se propõe a fazer uma análise de como é importante que o poder do Estado seja limitado. E para que isso aconteça é importante que haja normas que disciplinem a vida das pessoas em sociedade e também limite o próprio ente aplicador dessas normas.

Porém, para que fosse possível entender como acontece essa limitação do poder do Estado pelo direito, foi bastante importante considerar dados que expliquem a evolução destes estudos desde a concepção do que vem a ser o próprio Estado e aqui merecem destaque as teorias que expliquem seu surgimento e a necessidade de se criar esse poder. Da mesma forma, que se analisaram quais os poderes disciplinadores que o Estado possui, assim como a necessidade de se limitar esse poder para que não incorresse em abuso e prejudicasse os indivíduos que o constituiu, observando a sua importância na coletividade.

Tratar-se-á a questão do Estado com digressões históricas, mas temporalmente se tem como marco histórico a data em 30 de janeiro de 1648 (em Münster), quando se celebrou a chamada Paz de Vestfália, dando fim à Guerra dos Trinta Anos que praticamente dilacerou a Europa. Já o tratado de Vestfália foi assinado em 24 de outubro de 1648. Estas datas podem ser consideradas como o marco da fundação do Estado Moderno com suas fronteiras delimitadas, como se conhece hoje, pois foi a primeira vez em que se reconheceu a soberania de cada um dos Estados envolvidos. Este sistema de Estado-Nação foi redefinido com a Revolução Bolchevique na Rússia em 1917 e abalado com as duas Guerras Mundiais que tiveram por palco principal a Europa e que colocaram em risco a soberania do Estados nacionais. Atualmente este sistema de Estado nacional resiste e ainda tem sua importância, mas se vê claramente abalado por dois fenômenos que se ampliaram no século XXI: por um lado a Queda do Muro de Berlim (1989) e o Fim do Comunismo (1994), que juntamente com a revolução tecnológica e a emergência da internet e das redes sociais virtuais gerou um processo que se denominou de Globalização, que teve por consequência o enfraquecimento das fronteiras do Estado-Nação e o deslocamento dos recursos financeiros especulativos para a mão das corporações; por outro lado, o fenômeno do terrorismo de fundo religioso coloca outros princípios para o estabelecimento do poder, desconsiderando as fronteiras consideradas como artificiais por este movimento. Estes últimos fenômenos contemporâneos descritos anteriormente não são objeto desse estudo.

Espera-se que este estudo sirva como orientação para que os estudiosos no assunto possam entender que não se pode estudar o Direito sem fazer primeiro uma análise do que é Estado, uma vez que só existe o primeiro porque existe o segundo. Da mesma forma, que não se pode conceder um poder totalitário, absoluto, mas que precisa do Direito para disciplinar os poderes estatais. Não se desconhecem outras correntes importantes, que inclusive tem no Direito uma fonte fora do Estado, como é o Pluralismo Jurídico, mas este também não é objeto desse estudo.

Além disso, compreender como as pessoas podem, de acordo com as mudanças sociais, se tornar mais críticas e evitar que qualquer poder seja maior do que o próprio bem comum. Para que 
as pessoas comecem a viver de forma harmônica respeitando os direitos de seus semelhantes e não sendo lesado pelo próprio Estado. Em outras palavras, a administração pública não é uma mera burocracia, mas um sistema complexo eivado de vida e contradições.

\section{AS DIVERSAS CONCEPÇÕES DE ESTADO}

Muitos são os pensadores que teorizaram o surgimento da figura do Estado e suas principais características, trazendo as concepções do que vêm a ser a organização estatal.

Assim, a denominação "Estado” vem do latim “Status”, o que significa estar firme. Dessa forma, de acordo com os anos, essa palavra ia se enquadrando em várias concepções, desde a mais simples à mais ampla, obedecendo à mudança diacrônica da língua.

O que se pode notar é que vários autores se preocuparam em definir a palavra Estado em várias acepções, porém o que se pode perceber é que a grande maioria entendeu que se tratava de uma sociedade política.

Assim, para ser considerado Estado, precisa-se ir além do simples entendimento do que seja apenas algo fixo e considerado firme, predefinido; é importante que seja dotado de certas características e devem estar bem esclarecidas no contexto e que realmente se relacionem com os elementos que o constitui.

Dessa maneira, é interessante mencionar as diversas teorias que se formaram para definir o Estado. E antes de se falar na própria definição e o que vem a ser o Estado, é importante ressaltar as teorias de desenvolvimento da sociedade.

Por isso, de acordo com Dallari (2012, p. 17), “o Estado é universalmente reconhecido como pessoa jurídica, que expressa sua vontade através de determinadas pessoas ou determinados órgãos”. Assim, várias foram as teorias que surgiram para descrever também sociedade.

O primeiro grande pensador que se pode mencionar é Aristóteles, quando em suas sábias palavras afirmou que o ser humano é um animal político

Dessa maneira, Cícero, sec. I A.C apud Dallari (2012):

[...] a primeira causa da agregação de uns homens a outros é menos sua debilidade do que um certo instinto de sociedade em todos inato; a espécie humana não nasceu para o isolamento e para a vida errante, mas com uma disposição que mesmo na abundância de todos os bens, a leva a procurar o apoio comum.

De acordo com o pensamento do autor supracitado, é visível que vai na mesma linha de raciocínio de Aristóteles, pois reconhece o homem como produto social e que ele não é uma ilha, ou seja, que precisa dos outros para sobreviver.

Por outro lado, Santo Tomaz de Aquino apud Dallari (2012, p.22) traz três possibilidades de exceção ao pensamento desses filósofos, pois afirma que, quando o indivíduo está em três situações específicas, poderá viver isolado da sociedade.

A primeira quando o indivíduo, por meio de forças divinas, consegue ficar se alimentando da própria divindade, o que ocorria com os santos; a segunda quando os indivíduos possuem problemas mentais; e a terceira quando alguém se perde no meio do nada e consegue sobreviver isolado dos demais. 
Da mesma forma, os pensamentos de Hobbes no livro Leviatã traz a ideia de concepção anterior à concepção de estado. De acordo com ele, antes do Estado, os homens viviam no "estado de natureza", ou seja, era a "luta de todos contra todos".

$\mathrm{O}$ autor se refere a um estado antes de se realizar um contrato, visto que, de acordo com ele, os homens no estado de natureza são luxuosos e egoístas e devido aos objetos não terem donos, todos poderiam indistintamente disputá-los e aqui se pode até citar a autotutela como prérequisito, ou seja, a força física é que se determinava.

E esse conflito era dissipado quando surge a figura do contrato social, em que tem como elemento o Estado que moraliza e deixa claro o que é de quem. E de acordo com ele, até mesmo um mau governo é melhor que não se ter governança nenhuma. Como bem menciona Dallari (2012, p. 25), que no entendimento de Hobbes no estado é:

[...] uma pessoa de cujos atos se constitui em autora uma grande multidão, mediante pactos recíprocos de seus membros, com o fim de que essa pessoa possa empregar a força e os meios de todos, como julgar conveniente, para assegurar a paz e a defesa comuns.

Assim, o estado nesse sentido tem grande importância, visto que é ele quem disciplina a própria sociedade, disciplinando o bem comum e as melhores maneiras de sobrevivência e respeito mútuo.

Dessa maneira, seguindo o mesmo pensamento do autor, surgem outros autores que complementam essa teoria de Hobbes, como se pode citar Rousseau, de acordo com Dei Vecchio (2010, p.10):

\begin{abstract}
Rousseau procede, aqui, por hipóteses: chega a examinar a origem da civilização, que para ele é um desvio, uma corrupção do estado de natureza. Alguns homens mais fortes impuseram-se aos outros. "Aquele que por primeiro fechou um campo e disse: 'este é meu' foi o primeiro ator da infelicidade humana”. À propriedade privada agregou-se a dominação política; e assim, pelo domínio de certas paixões, um regime artificial de desigualdades pôs os homens em uma relação de dependência recíproca, contrária aos princípios naturais do seu existir. Determinou-se, em suma, uma antinomia profunda entre a constituição natural do homem e a sua condição social.
\end{abstract}

Nesse sentido, Rousseau acrescenta a ideia preestabelecida por Hobbes, uma vez que reafirma o aparecimento das normas sociais por meio da figura do Estado, pois fez com que os homens deixassem sua situação para se concentrar na figura do homem dentro de uma sociedade com as regras e com os ditames legais.

Dessa maneira, o Rousseau vai mais além ao relativizar a figura do estado como um disciplinador de direitos. Conforme dispõe Dei Vecchio (2010, p.106):

O direito natural de liberdade e de igualdade constitui o ponto de partida e a base da construção política de Rousseau. O Estado existe somente para a atuação desse princípio; portanto somente quando o seu ordenamento se conforma com isso ele é um verdadeiro Estado, ou seja, natural e racionalmente legítimo. Porque a liberdade e a igualdade devem ser conhecidas no Estado, não se segue que o Estado tenha tido origem no contrato; mas, ao contrário, o Estado devese supor originado do contrato para que aqueles direitos fundamentais sejam nele reconhecidos. 
Aqui surge uma concepção bem mais restrita de estado, não mais visto como posterior a um contrato, como mencionava Hobbes, mas pelo contrário, que os indivíduos dentro do estado já possuam os direitos principais de sobrevivência, como a liberdade e a igualdade. E a partir disso surge o contrato para que os direitos que ora possuem dentro da sociedade sejam finalmente reconhecidos.

Dessa forma, Rousseau entende que o indivíduo não está sozinho, mas que ele faz parte de um conjunto e que precisa estar bem socializado para que possa viver em harmonia, utilizando-se o lado racional, que é o que lhe faz diferente dos demais.

Por isso, até aqui se tratou de diversas formas de se conceber como surgiu o Estado, esse elemento em que está em superioridade com o indivíduo em particular.

Assim, o que se procurou até o momento foi entender o que seria um indivíduo em um mundo em que as pessoas não compreendessem os limites de seus direitos nem os limites de suas propriedades, sem dúvida seria uma verdadeira guerra entre indivíduo racionais. Visto que se o que diferencia o ser humano é o seu lado racional, então se não houvesse estado não haveria ser humano, pois todos seriam animais irracionais.

Mas como foi citado, o Estado ganhou uma nova concepção, pois passou a existir e a disciplinar a vida dos indivíduos, então é conveniente entender que ele possui inúmeras prerrogativas e diversos poderes, assunto que será debatido no próximo capítulo.

\section{O PODER DO ESTADO X DIREITO}

O estado, conforme foi estudado, é um elemento disciplinador das condutas dos indivíduos, o qual busca o bem comum. Dessa maneira, é interessante entender que, para que o estado tenha todo esse poder disciplinador, é imprescindível que ele possua atributos estabelecidos socialmente para cortar a "própria carne", ou seja, rever os atos dos membros que fazem parte do todo e, sempre prezando pela maioria, os quais devem possuir atributos para que se consiga limitar e equilibrar os direitos dos indivíduos dentro da sociedade.

Dessa maneira de acordo com Dallari (2012, p.114):

Para maior parte dos autores o poder é um elemento essencial ou uma nota característica do Estado. Sendo o Estado uma sociedade, não pode existir sem um poder, tendo este na sociedade estatal certas peculiaridades que o qualificam, das quais a mais importante é a soberania. Não há, também, uma distinção muito nítida entre poder de império e soberania […].

Assim, o autor deixa clara a grande característica para que se considere que o Estado é a soberania, uma vez que é a essência estatal e sem ser soberano, dificilmente se terá o poder.

Parte-se do ponto de vista que o Poder do Estado é diferente de qualquer dos outros poderes, pois se trata de um direito para todos. Assim, esse poder se fundamenta quando, além de se ter o poder, possui força dominante para impor essa prerrogativa.

Dessa maneira, é importante frisar que o que vem a ser norma é diferente do que está em um texto. Como bem menciona Mendes (2009, p.96):

A norma, portanto, não se confunde com o texto, isto é, com o seu enunciado, com o conjunto de símbolos linguísticos que forma o preceito. Para se encontrar

Parente Silva, J.W.; Portanova, R. 
a norma, para que se possa afirmar o que o direito permite, impõe ou proíbe, é preciso descobrir o significado dos termos que compõem o texto e decifrar, assim, o seu sentido linguístico.

Então o Estado se vale das normas verbais e não verbais para limitar o poder dos indivíduos e mostrar quem realmente domina todos, de uma forma geral e objetivando o bem comum. Essa é a principal finalidade estatal: buscar favorecer o maior número de indivíduo na sociedade. Do mesmo modo, vários doutrinadores entendem que considerar o poder do estado é considerar o poder político. E, assim, compreendem que se precisa de um poder específico para ditar e aplicar as normas que são criadas pela sociedade e que estão presentes dentro da sociedade e utilizadas com fins jurídicos. Sobre esse assunto Dallari (2012, p.115) esclarece:

[...] encontra-se na base de toda a vida social uma ordem jurídica, o verdadeiro sentido de poder ou dominação estatal não é o de que uns homens estão submetidos a outros, mas sim o de que todos os homens estão submetidos a normas. E quando se fala em poder do Estado como poder coativo isto quer dizer que as normas estatais, determinando certos comportamentos, prescrevem a coação para o caso de desobediência, isto porque são normas jurídicas.

Por isso, de acordo com as palavras do autor, não é simplesmente que os homens submetem limitações aos outros homens, pelo contrário, entendem que os homens devem estar submetidos às normas que são criadas dentro da sociedade. E que tais normas devem ser seguidas e respeitadas. Por outro lado, há também a importância que se dá às questões éticas e morais dentro da sociedade, uma vez que, de acordo do Reale (2001, p.39):

A teoria do "mínimo ético" pode ser reproduzida por meio da imagem de dois círculos concêntricos, sendo o círculo maior o da Moral, e o círculo menor o do Direito. Haveria, portanto, um campo de ação comum a ambos, sendo o Direito envolvido pela moral. Poder-se-ia dizer, de acordo com essa imagem, que "tudo o que é jurídico é moral, mas nem tudo que é moral é jurídico”.

Desse modo, não se pode falar em direito se não se falar primeiramente em moral, pois, segundo o autor, o direito está contido na moral, ou seja, é um subconjunto dela. Assim, como se sabe, muitas atitudes jurídicas são moralmente corretas, porém como o próprio Reale (2001) menciona, o oposto não é verdadeiro, visto que é bem visível e provável que nem tudo que é moralmente correto é jurídico.

Isso mostra como várias condutas morais deveriam estar positivadas, porém o que se percebe é que há uma nítida interferência do estado ao entender quais os direitos que disciplinam a moral social, e ele faz isso se utilizando do direito que possui.

Sendo assim, é bem claro como o Poder estatal é uma interferência muito importante e que disciplina as ações dos indivíduos, utilizando-se dos aspectos éticos e morais existentes. Isso com a finalidade de disciplinar o bem-estar social e tentar manter a ordem e a harmonia entre os seres humanos racionais.

Por outro lado, é importante mencionar que, mesmo que se tenha essa concepção do direito como sendo formado pela moral, mesmo assim é bem nítido que, muitas vezes, o direito disciplina o que não é moral como o próprio Reale (2001, p.40) esclarece:

O direito, infelizmente, tutela muita coisa que não é moral. Embora possa provocar revolta, tal fato não pode ficar no esquecimento. Muitas relações amorais ou imorais 
realizam-se à sombra da lei, crescendo e se desenvolvendo em meios de obstá-la. Existe, porém, o desejo incoercível de que o Direito tutele só o "ilícito moral, mas, por mais que os homens se esforcem nesse sentido, apesar de todas as providencias cabíveis, sempre permanece um resíduo de imoral tutelado pelo Direito”.

Por meio dessas palavras, confirma a abordagem feita anteriormente, pois é bem visível que as pessoas leigas pensem que o direito e a moral estão lado a lado, algo que não é verdade, visto que pelo tema "moral" ser extremamente amplo, e o poder do estado tentar disciplinar e através de métodos coercitivos fazer com que se estabeleçam normas que favoreçam os indivíduos de uma forma geral, podem acabar acontecendo determinadas ações intituladas pelo estado como legais, mas que não são morais.

E se chega à grande ideia desses questionamentos, pois como se vê, o direito pode ser exigido de forma coercitiva, já a moral não se pode utilizar da coerção para a sua aplicação.

Como bem menciona Reale (2001, p. 43), “ o que distingue o Direito da Moral, portanto, é a coercibilidade. Coercibilidade é uma expressão técnica que serve para mostrar a plena compatibilidade que existe entre o Direito e a força”. Assim, por meio do poder do estado, pode chegar a exigir o cumprimento de um direito que deverá ser seguido. Isso só acontece porque o estado possui a força para tutelar as ações dos indivíduos, pois de acordo com Reale (2001, p.44), “poderíamos definir Direito como sendo a ordenação coercitiva da conduta humana”, e de acordo com o autor foi o grande mestre Hans Kelsen (1999) quem definiu o direito.

E o autor ainda deixa claro que a coação está diretamente relacionada com a força estatal e no contexto ora em estudo é a prerrogativa fruto do poder estatal de disciplinador e regulador das ações dos membros que fazem parte da sociedade.

Sendo assim, de acordo com Del Vecchio (2010, p.104):

Para Rousseau, a lei não é outra coisa que não a expressão da vontade geral; não é, pois, um ato de comando arbitrário. Nenhum comando é legítimo, caso não se funde sobre a lei, isto é, sobre a vontade geral. Nesta vontade geral consiste na verdadeira soberania, que não pode, portanto, atentar para um indivíduo ou para uma corporação particular, mas sempre e necessariamente para o povo enquanto constitui um Estado.

Como é visível, Rosseau vem acrescentar a ideia de que a lei é a expressão da vontade da grande maioria dos indivíduos, mesmo que isso não esteja diretamente ligado à moral, mas que beneficie o maior número de pessoas possível, fazendo sempre prevalecer a maioria das ideias existentes, ou seja, aqui se acrescenta a ideia de soberania e de democracia, uma vez que sempre o desejo da maioria é concretizado.

Por isso, o Direito pode ser definido como um conjunto ordenado de regras que organizam a vida do homem em sociedade. Por isso, não se esgota apenas no estudo das normas jurídicas, englobando uma série de princípios e instituições capazes, no seu conjunto, de fornecer a caracterização da forma organizacional adotada por cada sociedade.

Nesse sentido, o Direito pode ser estudado tanto em sua gênese histórica quanto a partir de sua enunciação atual e concreta.

Falar em direito é falar de Kelsen (1999), um dos maiores pensadores do século XX, teórico do direito e do Estado, filósofo e sociólogo, além de iniciador da lógica jurídica, pois deixou uma vasta obra, da qual se destaca principalmente a Teoria Pura do Direito.

Parente Silva, J.W.; Portanova, R. 
Hans Kelsen (1999) apresentou na obra Teoria Pura do Direito uma concepção de ciência jurídica com a qual se pretendia ter alcançado, no Direito, os ideais de toda a ciência, quais sejam, a objetividade e a exatidão.

Para alcançar esses objetivos, Kelsen (1999) propôs uma depuração do objeto da ciência jurídica para garantir a autonomia científica para a disciplina jurídica que, segundo ele, vinha sendo deturpada pelos estudos sociológicos, políticos, psicológicos e filosóficos.

Kelsen (1999) propôs para a Ciência do Direito um princípio de pureza, segundo o qual o método e o objeto do direito deveriam ter enfoque normativo, livre de qualquer fato social ou outro valor transcendente.

Em sua teoria pura do direito, Kelsen (1999, p. 29) via o direito como regulador da conduta humana:

O Direito regula a conduta humana não apenas num sentido positivo - enquanto prescreve uma tal conduta ao ligar um ato de coerção, como sanção, à conduta oposta e, assim, proíbe esta conduta -, mas também por uma forma negativa - na medida em que não liga um ato de coerção à determinada conduta e, assim, não proíbe esta conduta nem prescreve a conduta oposta. Uma conduta que não é juridicamente proibida é - neste sentido negativo - juridicamente permitida.

Assim, segundo o autor, o direito é o regulador da conduta humana, tanto em sentido positivo como em relação às proibições, isso é o que faz com que seja efetivado o próprio direito existente.

Para Kelsen (1999, p. 92), o direito deveria também ser visto como ordem social na imposição de limites ao direito de propriedade:

Visto que o Direito, como ordem social, regula a conduta de indivíduos nas suas relações - imediatas ou mediatas - com outros indivíduos, também a propriedade só pode juridicamente consistir numa determinada relação de um indivíduo com outros indivíduos, a saber, no dever destes de não impedir aquele no exercício do seu poder de disposição sobre uma determinada coisa e não dificultar também de forma nenhuma o exercício desse poder de disposição.

Então, o direito pode determinar o domínio de uma pessoa sobre uma coisa e excluir os demais do domínio sobre esta mesma coisa.

A palavra Direito, do ponto de vista de Kelsen (1999), apresenta para todos os povos um significado comum de ordem à conduta humana, ordem esta que emana de uma norma superior responsável por dar validade às outras normas.

Kelsen (1999, p. 32-33) afirma que "uma norma singular é uma norma jurídica enquanto pertence a uma determinada ordem jurídica, e pertence a uma determinada ordem jurídica quando a sua validade se funda na norma fundamental dessa ordem".

Percebe-se, portanto, que, para Kelsen (1999), o Direito é também um emaranhado de normas que regulamentam as condutas sociais e são legitimadas pela Norma Fundamental, prescindindo de valoração legitimadora.

Portanto, é bem possível compreender que a vontade da maioria gera o poder estatal para disciplinar de uma forma geral e aplicar os benefícios gerais. Porém, esse poder também deve ser regulado, pois nem se pode ter poder maior do que foi estabelecido, nem aquém do necessário. 
Por esse motivo o direito vem disciplinar e mostrar que o Estado não pode usar da prerrogativa que possui para deixar de atender a maioria de seus membros. Assim, é importante observar os limites do poder do estado, assunto que será mais bem debatido no próximo capítulo.

\section{A LIMITAÇÃO DO PODER DO ESTADO PELO DIREITO}

Sabe-se que o Estado tem autonomia e, através de sua supremacia, pode-se ditar normas e regras que serão obedecidas pela sociedade, visto que, como foi estudado anteriormente, não é apenas uma noção de vontade, mas sim de sobrevivência, pois conforme foi estudado, antes do surgimento do estado, as teorias apontam uma vida irracional e sem respeito com o seu semelhante.

Assim, nos sistemas jurídicos modernos, as normas se restringem a regular o comportamento dos seres humanos com relação a seus semelhantes, animais e plantas, ao contrário das sociedades animistas do mundo primitivo no qual, por ordens supra-humanas, a conduta destes objetos com relação a seres humanos poderia ser regulada de forma legal. Este ato de regular dá-se em relação àquilo que a autoridade judiciária considera ou não valiosa à conduta humana.

É importante trazer ao debate o que vem a ser direito como fator primordial para limitar o poder do indivíduo, mas também limitar o poder estatal.

Por isso, de acordo com Oliveira Júnior (1994, p.115), na perspectiva de Bobbio, o direito é um “conjunto de regras de comportamento expressas em proposições normativas”.

Mas esta perspectiva linguística em Bobbio é bastante diferente daquela apresentada por Kelsen (1999), parte do mundo da lógica formal, em que o direito é visto não como um fato em si, mas como um valor.

Por esse motivo, pode-se ressaltar que, para Bobbio, o direito é uma entidade complexa, não sendo exclusivamente racional ou lógica, mas também um fato, uma realidade empírica e, desta forma, contextualizada historicamente.

Já Reale (2001, p.4) chegou a atribuir ao direito conceito semelhante ao de Kelsen (1999), quando garante que o direito é "um sistema de princípios e de regras a que os homens se devem ater em sua conduta; é um sistema de enlaces, destinados a balizar o comportamento dos indivíduos de qualquer idade ou classe social, bem como as atividades dos entes coletivos e do próprio Estado”.

Mas o destaque de Miguel Reale (2001) na conceituação do direito foi a criação da teoria tridimensional, na qual assegura que o direito é fato, valor e norma.

Reale (2001, p. 60) então afirma:

Uma análise em profundidade dos diversos sentidos da palavra Direito veio demonstrar que eles correspondem a três aspectos básicos, discerníveis em todo e qualquer momento da vida jurídica: um aspecto normativo (o Direito como ordenamento e sua respectiva ciência); um aspecto fático (o Direito como fato, ou em sua efetividade social e histórica) e um aspecto axiológico (o Direito como valor de Justiça).

A teoria tridimensional do Direito de Miguel Reale (2001) foi concebida como alternativa para essas concepções jurídicas de forte presença na realidade luso-brasileira e responsável por muitos de nossos problemas: os positivistas que enfatizam ora a norma, ora o fato e os idealistas focados nos valores distanciados dos fatos.

Parente Silva, J.W.; Portanova, R. 
Então, para Reale (2001), tais elementos ou fatores (fato, valor e norma) não existem separados um dos outros, mas coexistem numa unidade concreta, importante para a formação do direito. Assim, percebe-se que o Direito, na visão de Miguel Reale (2001), é, ao mesmo tempo, uno e multíplice.

Lembrando que as atitudes positivistas são muito criticadas por Reale (2001), já que para ele, os juristas, ao cultuarem exageradamente os textos legais, perdem o contato com a realidade e seus valores, pois quem cria as leis deve procurar interligar fatos e valores, atendendo, assim, aos anseios sociais daquele momento específico.

Portanto, o objetivo do Direito é regular a vida humana em sociedade, estabelecendo, para esse fim, normas de conduta que devem ser observadas pelas pessoas. Tem por finalidade a realização da paz e da ordem social, mas também vai atingir as relações individuais das pessoas.

O homem por natureza é um ser social. Vive em conjunto com os demais, necessitando de regras para regular essa situação. O Direito é fruto da convivência humana. Os valores giram em torno de alguns princípios fundamentais, respeitando-os.

Para Reale (2001), o valor da pessoa humana é o primeiro, pois é dele que partem todos os outros. A consciência coletiva, os objetivos da sociedade, formam um conjunto axiológico que possui superioridade ante os demais, pois ele assume um caráter permanente e universal, já que reflete o pensamento fundamental aceito pelo povo.

Os valores que compõem esse conjunto são chamados de invariantes axiológicas e abrangem, além do da pessoa humana, o direito à vida, à igualdade perante a lei, à liberdade individual, ou seja, aos direitos fundamentais do homem. Podem sofrer variações de sentido dependendo de novos fatos que surjam - que irão ampliar seu alcance, mas não irão extingui-los.

Já para Kant (2003, p. 407), o direito não está relacionado a fato, valor e norma, mas sim a uma relação de obrigações que unem os homens:

O direito estrito fundamenta-se sem dúvida na consciência da obrigação de cada um adequar-se à lei; (...) esse direito apoia-se unicamente sobre o princípio da possibilidade de uma coerção externa que possa coexistir com a liberdade de cada um, segundo as leis gerais.

Pode-se dizer que, segundo Kant (2003), o direito é a liberdade de cada um de maneira que todas as liberdades externas possam coexistir segundo uma lei universal.

Por isso, o direito é o que possibilita a livre coexistência dos homens, isso acontece em nome da liberdade, porque somente quando a liberdade é limitada, não se transforma em uma não liberdade para os outros. Dessa maneira, cada um pode usufruir da liberdade que lhe é concedida pelo direito de todos os outros de usufruírem de uma liberdade igual à dele.

O Direito procura realizar a liberdade na plenitude, na medida em que torna possível seu exercício externo, limitando o arbítrio dos indivíduos de forma igual, no sentido de tornar possível o pleno exercício, em sociedade, do maior de todos os bens do homem: a liberdade.

Do exposto resta claro que sua concepção jurídica de Kant (2003) é tipicamente liberal, ou seja, centrada da liberdade individual e formalista, ou seja, desvinculada de fins ou valores.

Outro grande jurista, Santi Romano (2008), também tentou definir o direito e para isto elaborou uma concepção de ordenamento jurídico propondo uma identificação institucionalista do mesmo. 
Para tanto, Romano (2008) percorre desde a emanação do direito por meio da "necessidade social” até a constituição de um concreto estado plural de ordenamentos, alicerçando, por conseguinte, a construção de um conhecimento jurídico antiformalista. Romano (2008, p 66) fala que o direito não é apenas o positivado, mas também consuetudinário:

[...] uma ou mais normas determinadas - uma lei, um costume, um código e assim por diante - considerando-as cada uma em si ou mesmo agrupando-as materialmente, segundo o seu objeto comum, a sua fonte, o documento que as contém, ou outros critérios mais ou menos extrínsecos e particulares. Neste caso, a definição comum parece perfeitamente exata.

De acordo com as palavras de Romano (2008), as normas se agrupam materialmente levando em consideração o objeto que elas têm em comum. E por isso que são tão importantes a definição e a conexão que possuem e que se interligam.

No mesmo contexto, Romano (2008, p. 60) ainda cita que ordenamento jurídico seria o próprio direito:

[… entende-se por direito algo não somente mais amplo, mas também substancialmente diferente. Isso se verifica quando diz respeito a todo o ordenamento jurídico de um ente: quando, por exemplo, se fala do direito italiano ou francês, do direito da Igreja católica etc. abraçando cada um na sua respectiva totalidade. Então, é necessário e correr a um expediente para sustentar a definição geralmente adotada: o de conceber cada um destes ordenamentos como um conjunto ou um sistema de normas.

Romano (2008) ainda destaca que não há sociedade sem direito e não há direito sem sociedade, portanto pensar em direito é pensar em sociedade, e pensar em sociedade é pensar em organização, indubitavelmente, pensar em organização é pensar em direito e vice-versa.

Romano (2008) adverte que todo e qualquer elemento que poderia levar à noção de desordem, como puro arbítrio ou força material, deveria ser excluído do conceito do direito.

Assim, o direito é visto pelo autor como uma linguagem não só lógica ou axiomática, mas como uma linguagem natural multi-problemática, envolvida com complexas circunstâncias históricas.

Então, por tudo o que foi até aqui abordado, surge a noção de Direito aplicado aos indivíduos e também ao próprio Estado, pois deve ter seu poder limitado pelo direito, uma vez que é por meio de seu poder que ele se impõe e cobra dos indivíduos melhor comportamento social.

Por outro lado, não se pode entender esse poder de forma absoluta e que possa ir de encontro a tudo e a todos, pois se a finalidade do poder é trazer benefícios para a sociedade, como trará esses benefícios se utilizando do direito de maneira abusiva e irrestrita.

Por esse motivo, aparece a figura do direito como guardião social e limitador desse poder que o estado possui. Desse modo, é importante esclarecer o que vem a ser abuso de poder.

E, além disso, sentiu-se a necessidade de criar elementos que coibissem também esse abuso de poder, pois se isso não acontecesse, provavelmente iria prejudicar os próprios seres humanos que tutelaram o poder do estado. Nesse contexto, surgiu a figura do abuso de poder. E como a legislação atua para coibir o abuso de poder? 
De acordo com Mendes (2012, 53): Essa liberdade necessita ser assegurada por uma Constituição que previna o abuso do poder, já que "todo homem que tem poder é tentado a abusar dele; vai até onde encontra limites”. E o meio apto para a sociedade se precatar contra o desmando seria a correta "disposição das coisas", propícia a que "o poder freie o poder". Daí a separação entre os Poderes para que um contenha o outro. Esses Poderes são identificados como Legislativo, Executivo das coisas que dependem do direito das gentes e Executivo das que dependem do direito civil. Sobre os dois "Executivos", Montesquieu diz: "chamaremos este último o poder de julgar e, o outro, simplesmente o poder executivo do Estado”.

Mendes (2012) traz à tona a divisão dos poderes feita por Montesquieu, pois observando a tendência ao abuso do poder, pensou-se em limitá-lo, visto que, mesmo o estado sendo "esse ser maior" que está acima dos indivíduos que o constituem, ainda assim, precisa está representado por uma pessoa escolhida, muitas vezes pelo povo.

Por esse motivo, era de inteira importância que se criassem elementos para disciplinar a atuação estatal. Por isso, surge, como foi visto nas palavras de Mendes (2012), a figura da separação dos poderes como forma de limitar e descentralizar o poder estatal, uma vez que esse direito não deveria ficar na mão de uma só pessoa, o que possibilitaria o desmembramento do poder e poderia sofrer menos com o abuso totalitário de direito.

Desse modo, surge então a ideia de uma legislação maior que traga uma segurança para os indivíduos que, ao escolher um representante estatal, ele possa seguir os ditames de uma legislação específica, o que fará com que os governantes temam e evitem abusar do direito que lhe foi concedido.

Sendo assim, como bem menciona Di Pietro (2013, p.38):

A Administração Pública tem que ter prerrogativas que lhe garantam a autoridade necessária para a consecução do interesse público. Ao mesmo tempo, o cidadão tem que ter garantias de observância de seus direitos fundamentais contra os abusos do poder. Esse binômio autoridade/liberdade está presente em todos os institutos do direito administrativo. Na evolução desse ramo do direito, pode o pêndulo do relógio pender mais para um lado do que para o outro. O ideal é que haja um equilíbrio.

Por isso, uma das grandes importâncias do administrador é o fator poder, poder esse que é o mesmo poder estatal, porém de acordo com as palavras da Di Pietro (2013), deverá estar limitado pelo direito, uma vez que o exercício deve ser voltado a atender as garantias legais e respeitando os direitos fundamentais dos indivíduos, o que limita qualquer tentativa de abuso de poder.

Assim, é importante que o direito discipline as ações humanas para que os indivíduos vivam em harmonia, e aqui se deixou claro o direito do administrador, visto que, apesar de cada poder ter seu poder típico, eles também possuem as suas funções atípicas e a maioria das funções correlacionadas diz respeito à função de administrar.

Dessa maneira, é perceptível que o Estado é composto pelo entrelaçamento de comportamentos jurídicos e, também, políticos. Por isso, a grande importância dada ao direito, para que, ao mesmo tempo que discipline as relações na sociedade, possa evitar qualquer tipo de abuso de direito e que prevaleça a ideia de respeito e isonomia dentro de uma comunidade.

Desse modo, é fácil perceber como há, muitas vezes, um desvio dentro de várias esferas jurídicas. Agentes tendentes a se desviar total ou parcialmente no momento de se aplicar a norma 
ou tentar ludibriar o direito pelo simples fato de estarem ocupando determinadas posições de prestígio na sociedade. Assim sendo, é muito importante observar os limites legais ou até mesmo quais as atribuições de cada agente detentor de poder na sociedade. Portanto, ao se falar em abuso de poder, se está falando em um campo muito amplo de ações ou omissões diante do direito material, e levando em consideração as ações dos agentes que têm o dever ou o não dever de aplicar a norma jurídica na sociedade.

\section{CONSIDERAÇÕES FINAIS}

Antes de se falar em Direito, foi preciso primeiro conhecer esse elemento social que é o Estado. Dessa forma, as diversas teorias que o fundamentam são de crucial importância para a sua definição. Desde o pensamento de Tomas Hobbes ao pensamento de Rousseau, sempre buscando analisar por que o Estado é importante para a sociedade, pois se não houvesse estado, não haveria civilização, como o próprio Hobbes já havia definido os homens em seu estado de natureza.

Ao logo das discussões, começou a analisar o poder que é atribuído ao direito. Uma vez que, ao ser dado ao estado tamanho poder, foi importante criar mecanismo de combate a esse poder absoluto e, por vezes, abusivo, que o estado poderia se valer contra os indivíduos que o criou e instituiu.

Por esse motivo, surgiu a noção de limitação do poder do Estado pelo Direito, visto que o Direito procura realizar a liberdade na plenitude, na medida em que torna possível seu exercício externo, limitando o arbítrio dos indivíduos de forma igual, no sentido de tornar possível o pleno exercício, em sociedade, do maior de todos os bens do homem: a liberdade. Em seu caráter evolutivo, o direito também incorporou valores, como a igualdade, não só formal, mas também material, como no caso dos Direitos Sociais e mais recentemente a solidariedade, que redefine o princípio revolucionário francês da fraternidade (pode-se falar em solidariedade geracional, de gênero, étnicas, etc.).

Por esse motivo, aparece a figura do direito como guardião social e limitador desse poder que o estado possui, pois todos os entes dotados de poderes também são compostos de deveres e esses poderes não devem estar além nem aquém, deverão estar disciplinados na medida certa. E a forma que regula essa balança é exatamente o Direito.

\section{REFERÊNCIAS}

DALLARI, D. de A. Elementos de teoria geral do Estado. 31. ed. São Paulo: Saraiva, 2012.

DEI VECCHIO. História da filosofia do direito. Belo Horizonte: Líder, 2010.

DI PIETRO, M. S. Z. Direito administrativo. 27. ed. São Paulo: Atlas, 2014.

KANT, I. A Metafísica dos Costumes. São Paulo: Edipro, 2003.

MENDES, G. F. Curso de direito constitucional. 4. ed. São Paulo: Saraiva, 2009.

KELSEN, H. Teoria Pura do Direito. São Paulo: Martins Fontes, 1999.

OLIVEIRA JÚNIOR, J. A. de. Bobbio e a filosofia dos juristas. Porto Alegre: Fabris Editor, 1994.

REALE, M. Lições Preliminares do Direito. 5. ed. São Paulo: Saraiva, 2001.

ROMANO, S. Ordenamento Jurídico. Florianópolis: Fundação Boiteux, 2008.

Parente Silva, J.W.; Portanova, R. 